\title{
Analysis of smooth muscle function in IRAG knockout mice
} Matthias M Desch*1, Katja Sigl2 ${ }^{2}$, Beate Spiessberger ${ }^{2}$, Dominik Bernhard², Angela Jochim ${ }^{2}$, Jörg W Wegener ${ }^{2}$, Franz Hofmann ${ }^{2}$ and Jens Schlossmann ${ }^{1,2}$

Address: ${ }^{1}$ Institut für Pharmakologie und Toxikologie, Universität Regensburg, Germany and ${ }^{2}$ Institut für Pharmakologie und Toxikologie, TU München, Germany

Email: Matthias M Desch* - matthias.desch@chemie.uni-regensburg.de

* Corresponding author

from $3^{\text {rd }}$ International Conference on cGMP Generators, Effectors and Therapeutic Implications

Dresden, Germany. I5-17 June 2007

Published: 25 July 2007

BMC Pharmacology 2007, 7(Suppl I):PI4 doi:I0.II86/I47|-22 I0-7-SI-PI4

This abstract is available from: http://www.biomedcentral.com/I47I-22I0/7/SI/PI4

(C) 2007 Desch et al; licensee BioMed Central Ltd.

Signaling by NO/cGMP relaxes various smooth muscles, modulating thereby vascular tone and gastrointestinal motility. An important signaling pathway of cGMPdependent protein kinase type I (cGKI)-dependent relaxation is mediated by IRAG ( IP $_{3}$ Receptor Associated cGKI substrate) which is highly expressed in smooth muscle tissues. In order to elucidate the physiological role of IRAG we generated IRAG knockout mice by targeted deletion of exon 3.

The cGMP dependent relaxation of hormone induced contraction on gastrointestinal tissues of colon and jejunum as well as aortic vessels is significantly affected in IRAG knockout mice in comparison to wild type animals. The analysis of smooth muscle function indicates that IRAG is essentiaI for $\mathrm{NO} / \mathrm{cGMP} / \mathrm{cGKI}$ signaling, especially for regulating muscular tone. 